\title{
COMUNICAÇÃO
}

\section{METACICLOGÊNESE DO TRYPANOSOMA CRUZI COMO PARÂMETRO DE INTERAÇÃO DO PARASITA COM OTRIATOMÍNEO VETOR}

\author{
Nelson J. Alvarenga e Elisabeth Bronfen
}

\begin{abstract}
Triatoma infestans infectados por três amostras do Trypanosoma cruzi permitiram observar: 1) variabilidade numérica de metacíclicos obtidos de cada amostra após diferentes períodos de infecção; 2) diferenças na perda da infecção de acordo com a amostra infectante e 3) a relação entre o número de parasitas ingeridos e metacíclicos obtidos posteriormente.

Palavras-chaves: Trypanosoma cruzi. Metaciclogênese. Interação com Triatoma infestans.
\end{abstract}

A morfogênese do Trypanosoma cruzi no trato digestivo de seus vetores envolve transformações do tripomastigota ingerido que vão desde sua passagem por esferomastigotas e/ou epimastigotas as quais, após uma série de divisões, dão origem aos tripomastigotas metacíclicos fechando o ciclo evolutivo deste flagelado1. Tais fenômenos morfogênicos são decorrentes de alterações fisiológicas sofridas pelo parasita que além de estar se nutrindo de produtos de secreção intestinal 2 e produtos de digestão do sangue ingerido pelo inseto vetor, certamente estará sofrendo a ação de fatores digestivos e hemolíticos 3 que podem atuar como inibidores ou não de sua evolução. Daí, podermos interpretar como sendo característica inerente a uma certa amostra de T. cruzi, em interação com determinada espécie de vetor, a apresentação de uma proporcionalidade entre o número de epimastigotas, esferomastigotas e tripomastigotas metacíclicos. Naturalmente, levando-se em consideração o tempo de infecção e a regularidade das realimentações.

Pela observação da interação de três amostras do T. cruzi com espécimes de Triatoma infestans experimentalmente infectados, estudou-se a variabilidade numérica de tripomastigotas metacíclicos no intestino dos insetos; o

Laboratório de Biologia de Triatomíneos e Epidemiologia da Doença de Chagas, Centro de Pesquisas René Rachou/FIOCRUZ, Belo Horizonte, MG, Brasil.

Endereço para correspondência: Dr. Nelson J. Alvarenga. Centro de Pesquisas René Rachou. Av. Augusto de Lima 1715,30190-002 Belo Horizonte, MG, Brasil. Fax:(031) 295-3115. Recebido para publicação em 25/04/96. percentual de perda de infecção e a variação numérica de metacíclicos contidos nos intestinos daqueles que tenham ingerido diferentes números de tripomastigotas sangüíneos.

Variabilidade numérica de tripomastigotas metacíclicos. Ninfas de terceiro estágio de $T$. infestans foram alimentadas em camundongos previamente infectados pelo $T$. cruzi, pelas amostras Y10, CL4 e Yú-Yú (isolada a partir de T. infestans naturalmente infectado e mantida no laboratório por passagem periódica de camundongo a camundongo). Para cada amostra foram utilizados 40 insetos que tiveram seus repastos acompanhados individualmente de modo a se evitar total ingurgitamento. Utilizando câmara de Neubauer, procedeu-se a contagem do número de tripomastigotas na circulação dos camundongos por retirada de 10ul de sangue, diluído em PBS (pH 7.2). Em seguida realizou-se o cálculo do número ingerido por cada triatomíneo, pelas diferenças dos pesos obtidos antes e após a alimentação, considerando ser o peso de $1 \mu$ ligual a $1 \mathrm{mg}$. A média de tripomastigotas das amostra Y, CL e Yú-Yú ingeridos por inseto foi de 9.000, 4.300 e 7.100, respectivamente. Os triatomíneos foram mantidos a $25^{\circ} \mathrm{C}$ e $70 \%$ de umidade relativa, sendo realimentados a cada 20 dias em camundongos não infectados. Após 30, 60, 90 e 120 dias foram dissecados 10 exemplares de cada lote e seus intestinos retirados e macerados, em "pool", em "tissue-grinder" , em $3 \mathrm{ml}$ de PBS. A contagem diferencial dos parasitas foi feita em câmara de Neubauer, em microscopia de contraste de fase, e os resultados considerados a partir das médias 
Comunicação. Alvarenga NJ, Bronfen E. Metaciclogênese do Trypanosoma cruzi como parâmetro de interação do parasita com o triatomineo vetor. Revista da Sociedade Brasileira de Medicina Tropical 30:247250, mai-jun, 1997.

obtidas de 3 amostragens. Entre 30 e 90 dias após a infecção observou-se um aumento quase contínuo nas populações de metacíclicos. Após 90 dias de infecção não mais se observou este aumento de tripomastigotas sugerindo a finalização do processo de colonização do parasita ao longo dos intestinos dos triatomíneos (Figura 1).

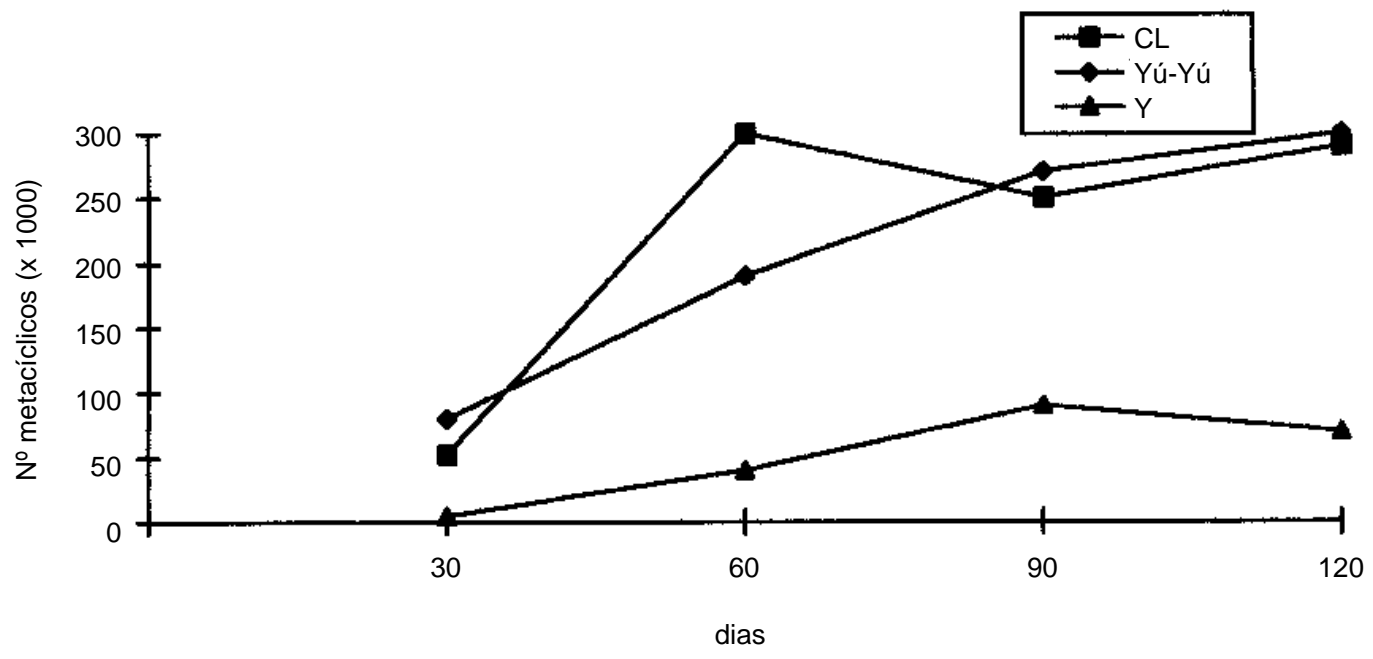

Figura 1- Observação da tendência à estabilização na curva de crescimento numérico de tripomastigotas metacíclicos de três amostras do Trypanosoma cruzi no intestino de Triatoma infestans aos 30, 60, 90 e 120 dias após a infecção.

Percentual de perda de infecção pelo $\mathrm{T}$. infestans. Três grupos, A, B e C, de 100 ninfas de terceiro estágio de T. infestans, foram respectivamente alimentados em camundongos previamente infectados pelas mesmas amostras do T. cruzi. Em separado, outro grupo, D, de 50 triatomíneos, foi infectado pela amostra YúYú. Os insetos foram mantidos nas condições descritas anteriormente sendo realimentados a cada 20 dias, com exceção do grupo D que foi mantido em jejum por 60 dias. Aos 30, 60, 90, 120 e 150 dias após a infecção, 20 insetos dos grupos A, B e C foram dissecados e seus intestinos retirados. Cada intestino foi macerado


foram examinadas (50 campos) utilizando-se microscopia de fase (160x). Os resultados demonstraram que já aos 30 dias após infecção não foi possível perceber a presença de flagelados no conteúdo intestinal em mais de $25 \%$ dos triatomíneos infectados pela amostra $\mathrm{Y}$, confirmando as observações descritas anteriormente 5 no que se refere à má interação da amostra Y com o T. infestans. A não detecção de infecção do vetor pelas outras duas amostras se fez notar somente após 60 dias, mesmo assim em níveis de negatividade diferentes dos observados em relação à amostra Y que aparenta uma perda crescente de parasitas (Figura 2).

Os triatomíneos do grupo $\mathrm{D}$, mantidos em jejum por 60 dias, foram então realimentados e em seguida mantidos isoladamente 11 durante 4 horas para coleta de urina e verificação da presença de flagelados. Foram 23 os animais cujas urinas apresentaram-se negativas em exames (50 campos) de duas amostragens de $10 \mu l$ cada. Destes, 11 foram dissecados e tiveram os intestinos médios e retos macerados individualmente em

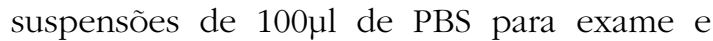
contagem de tripomastigotas em câmara de Neubauer. Nos intestinos, constatou-se a média de 2.000 tripomastigotas $/ \mathrm{ml} /$ inseto juntamente com inúmeros epimastigotas. A nível de reto foram observados raros epimastigotas com baixa mobilidade ou mesmo imóveis, e nenhuma forma tripomastigota. Cinco dias após a realimentação outros 11 triatomíneos foram dissecados tendose procedido como anteriormente para exame e contagem do parasita. Nos intestinos, a média de tripomastigotas metacíclicos observados foi 
Comunicação. Alvarenga NJ, Bronfen E. Metaciclogênese do Trypanosoma cruzi como parâmetro de interação do parasita com o triatomíneo vetor. Revista da Sociedade Brasileira de Medicina Tropical 30:247250, mai-jun, 1997.

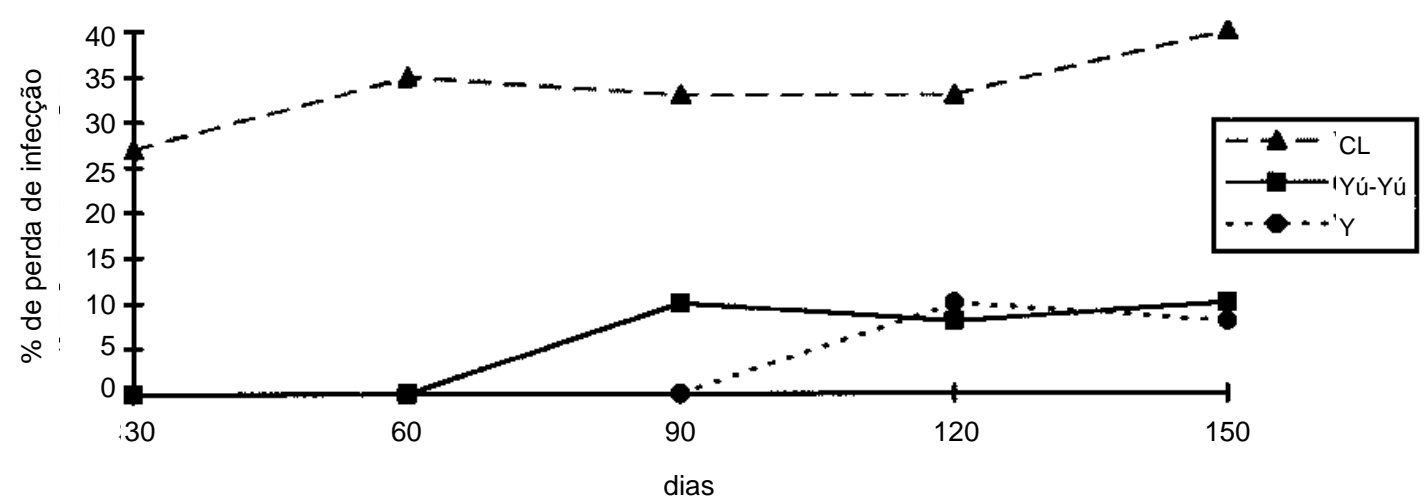

Figura 2 - Percentual de triatomíneos negativos após exames aos 30, 60, 90, 120 e 150 dias de infecção por três amostras do T. cruzi.

de $2.700 / \mathrm{ml} /$ inseto. Nas ampolas retais, a média foi de $4.300 / \mathrm{ml} /$ inseto. Este experimento mais uma vez demonstrou a presença de tripomastigotas metacíclicos no intestino médio dos triatomíneos ${ }^{1}$ e também a possibilidade de erro ao considerar-se um exame negativo somente pela observação do conteúdo da ampola retal após a compressão abdominal.

Relação entre o número de tripomastigotas ingeridos e metacíclicos formados. Cinqüenta ninfas de $3^{\circ}$ estágio de $T$. infestans previamente pesadas, foram alimentadas sob observação em camundongos infectados pela amostra YúYú do T. cruzi apresentando parasitemias numericamente conhecidas. Após a pesagem e cálculo de tripomastigotas ingeridos, os insetos foram separados em dois grupos de 15 exemplares cada. As médias de parasitas ingeridos foram 2.699 e 50.266 flagelados por inseto do grupo A e $\mathrm{B}$, respectivamente. Os triatomíneos foram mantidos em condições já descritas, sendo realimentados em camundongos normais aos 20, 40 e 60 dias após o repasto infectante. Aos setenta dias pós-infecção, os insetos foram dissecados e seus intestinos macerados individualmente para contagem de tripomastigotas. Os resultados mostraram que o número de metacíclicos observados foi praticamente o mesmo para os dois grupos e não vinte vezes maior a favor do grupo B, demonstrando haver realmente uma tendência à estabilização numérica da população de flagelados ao longo do trato intestinal dos triatomíneos. Tal fato não seria possivel se a população final de flagelados fosse a representação diretamente resultante do número de parasitas ingeridos (Tabela 1).

Tabela 1- Tripomastigotas metacíclicos do conteúdo intestinal de triatomíneos infectados há 70 dias por diferentes números de formas sanguíneas do T. cruzi.

\begin{tabular}{ccc}
\hline Grupo & ingeridos/inseto & metacíclicos $/ \mathrm{ml}$ \\
\hline $\mathrm{A}$ & 2.699 & 220.000 \\
$\mathrm{~B}$ & 50.266 & 290.000 \\
\hline
\end{tabular}

Pelo presente estudo foi possível observarse que as amostras de T. cruzi, quando bem adaptadas ao inseto vetor, tendem a atingir determinada densidade populacional no intestino do triatomíneo num certo tempo e durante o crescimento do inseto, tanto pela ocupação do espaço físico disponível como por seleção pelo material alimentar secretado pelos insetos. Tal fato leva a que se considere também a tendência à estabilização numérica de tripomastigotas metacíclicos encontrados nos intestinos dos triatomíneos. Naturalmente, tudo isto em dependência da regularidade na alimentação dos insetos considerando-se que o processo de metaciclogênese está diretamente relacionado com a hemoglobina ingerida7.

Os dados fazem refletir sobre a necessidade de um melhor conhecimento da fisiologia dos diversos clones das amostras do T. cruzi bem como das espécies de vetores6, pois até o momento a utilização de triatomíneos em xenodiagnósticos ou isolamentos do parasita têm sido feitos com base em observações de casuísticas epidemiológicas 89. 
Comunicação. Alvarenga NJ, Bronfen E. Metaciclogênese do Trypanosoma cruzi como parâmetro de interação do parasita com o triatomineo vetor. Revista da Sociedade Brasileira de Medicina Tropical 30:247250, mai-jun, 1997.

\section{SUMMARY}

Infection of Triatoma infestans with three different strains of Trypanosoma cruzi permited to observe: 1) numerical variability of metacyclics obtained after different times; 2) the differences of loss of infection according to each strain; 3) the relationship between ingested parasites and later obtained metacyclics.

Key-words: Trypanosoma cruzi. Metacyclogenesis. Interaction with Triatoma infestans.

\section{REFERÊNCIAS BIBLIOGRÁFICAS}

1. Alvarenga NJ. Evolução do Trypanosoma cruzi no trato intestinal do Triatoma infestans. Tese de Mestrado, Universidade Federal de Minas Gerais, Belo Horizonte, MG, 1974.

2. Alvarenga $\mathrm{NJ}$, Brener $\mathrm{Z}$. Development of Trypanosoma cruzi in the vector in the absense of blood.Acta Tropica 35:315-317, 1978.

3. Azambuja P, Mello CB, Déscoffier LN, Garcia E. In vitro cytotoxicity of Rhodnius prolixus hemolytic factor and mellitin towards different trypanosomatids. Brazilian Journal of Medical and Biological Research 22:597-599, 1989.

4. Brener Z, Chiari E. Variações morfológicas observadas em diferentes amostras do Trypanosoma cruzi. Revista do Instituto de Medicina Tropical de São Paulo 5:220-224, 1963.

5. Bronfen E, Dias JCP, Gouveia SC. Infecção experimental de Triatoma infestans e Panstrongylus megistus pela cepa Y do Trypanosoma cruzi (Silva e Nussenweig, 1953). Revista de Patologia Tropical 13:1-7, 1984.
6. Garcia E, Azambuja P. Development and interactions of Trypanosoma cruzi within the insect vector. Parasitology Today 7:240-244, 1991.

7. Garcia ES, Gonzalez MS, Azambuja P, Baralle FE, Fraidenraich D, Torres HN, Flawía MM. Induction of Trypanosoma cruzi metacyclogenesis in the gut of the hematofagous insect vector, Rhodnius prolixus, by hemoglobin and peptides carrying $\alpha$ D-globin sequences. Experimental Parasitology 81:255-261, 1995.

8. Nirchl RA, Soares Junior JM, Pirani EM, Franciscon JH, Ramirez LE. Susceptibilidade do Triatoma infestans a diferentes cepas do Trypanosoma cruzi isoladas de pacientes chagásicos do triângulo mineiro. Revista da Sociedade Brasileira de Medicina Tropical 27:235-239, 1994.

9. Perlowagora-Szumlewicz A, Muller CA, Moreira CJC. Studies in search of a suitable experimental insect moel for xenodiagnosis of hosts with Chagas' disease. 3- On the interaction of vector species and parasite strain in the reaction of bugs to infection by Trypanosoma cruzi. Revista de Saúde Pública de São Paulo 22:390-400, 1988.

10. Silva LHP, Nussenweig V. Sobre uma cepa de Trypanosoma cruzi altamente virulenta para o camundongo branco. Folia Clinica e Biologica 20:191-207, 1953.

11. Zeledón R,Alvarenga NJ, Schosinsky K. Ecology of Trypanosoma cruzi in the insect vector. Chagas' Disease Symposium Proceedings, Pan American Health Organization, Scientific Publication 347:59-70, 1977. 